Since chemical action involves an alteration in the magnitude of the dipole moment of at least a portion of the reacting molecule, this method is found most convenient for following rates of reaction which may involve either an interaction between molecules in the film with those in one of the bulk phases, or interaction between molecules existing in the film itself. In this latter case, a more or less continuous polymeric film can be built up. Such polymeric films present interesting properties in respect to their elastic behaviour when solid and in their viscosity when liquid, and merit detailed examination.

Since in many cases the molecular orientation in the monolayer can be affected by a change in pressure exerted on the film, it is possible to examine the effects of molecular orientation in the kinetics of film reactions. Very remarkable changes in reaction velocity can be effected in some cases by a minute change in the surface tension ; furthermore, in photo-chemical reactions in films we can control the extinction coefficient and thus the quantum efficiency of surface photo-chemical action.

In addition to such enzyme and chemical reactions, it is also possible to examine those loose molecular associations frequently termed 'complexes' in some detail. We have already referred to the adsorption of digitonin by cholesterol, and similar reactions are involved with other glucosides such as saponin and even with much simpler molecules. Thus long-chain alcohols, especially secondary alcohols, and long-chain acids, form remarkably stable mixed films, although no ester formation is involved. These complexes involve interaction between both the polar head groups and also between the non-polar chain or ring systems of the reactants. Many of the polar head group interactions can be interpreted in terms of a hydrogen bond, but both dipole - dipole and dipole - ion interactions are also involved. The film technique also permits us to examine the mechanism of penetration of one molecular species into a monolayer of another, and here again both polar and non-polar portions of each molecular species are involved. It is also possible to examine the anchoring together of a number of molecules in the surface monolayer by a polymeric substance introduced into the substrate, for example, the polyphosphoric acid systems on calcium stearate or tannin on a protein.

The method reveals that these molecular associations involving free energy changes of the approximate order of $\Delta F=10,000$ cal. are extremely common in those relatively complex organic compounds met with in biological fluids, and it does not seem unreasonable to assume that they are actually present in living systems. For example, lipoids and proteins form lipoprotein films possessing interesting properties, and we might anticipate the presence of such lipoproteins in sera containing both proteins and lipoids. We might emphasize the remarkable degree of specificity obtainable not only by a change in the orientation of a polar group, but also by a similar change in orientation, for example, by movement of a double bond in the nonpolar portion of the molecule.

Whilst it is possible to examine the polar and non-polar interaction separately by this method, much further work is required before a definite statement as to the actual number of bonds and the individual bond energies involved can be made. This goal is important in that it will then permit us to calculate, as Eyring has pointed out, the absolute reaction rates. But it is at least interesting to note that in a protein 'complex' we are satisfied by this experimental technique that a large number of bonds are involved. The process of denaturation must involve, according to theory, the breaking of a large number to form the activated state for denaturation. ERIC K. RIDEAL.

\title{
French Society of Chemical Industry
}

\section{Seventeenth Congress in Paris}

$\mathrm{U}^{\mathrm{N}}$ DER the presidency of Sir Robert Mond, member of the Institut de France, the Société de Chimie Industrielle held its seventeenth Congress and at the same time celebrated the twentieth anniversary of its foundation by the late M. Paul Kestner, between the dates of September 26 and October 3. Arrangements made by various committees presided over by M. J. Gérard, M. J. Bougault and M. G.-J. Painvin, were appreciated by a large gathering of French chemists and about two hundred and fifty delegates from different countries, including more than twenty from Great Britain. British delegates bearing congratulatory addresses were sent by the Royal Society, the various chemical societies and the Institute of Metals.

After the proceedings had been opened in the large hall of the Maison de la Chimie by the UnderSecretary of State for Commerce, Sir Robert Mond gave an address on the evolution of the 
nickel industry, and in the same hall, throughout the Congress, were delivered important addresses on such subjects as the chemistry of silicates, by M. Artigas (Madrid), corrosion of metals, by Prof. W. J. Müller (Vienna), sterols, by Prof. I. M. Heilbron (Manchester), and the influence of fundamental research on daily life, by Dr. I. Langmuir (United States). In the Hall of the Sorbonne, M. Georges Claude gave a two hours' lecture with experimental demonstrations on the part he had played in utilizing acetylene, liquefying gases, separating the rare gases, and an account of his attempts (illustrated by a film) to obtain by pumping cold water from great depths of the sea such a temperature difference as would enable an engine to be worked.

Sectional meetings were held in numerous branches of applied chemistry, and to these contributions were made by the following British chemists: J. Muir, on dyeing of fabrics; Prof. C. S. Gibson, on the production of gold mirrors ; Sir Robert Robertson, on some of the work of the Water Pollution Research Board; and Dr. F. S. Sinnatt, on hydrogenation.

At the closing session, the President of the French Republic being present, addresses were given by Sir Robert Mond and others on the history and influence of the Société de Chimie Industrielle, and at this ceremony were presented new honorary members of the Society. These included Prof. F. G. Donnan, president of the Chemical Society.

It will, of course, be readily believed that the occasion was marked by characteristic French ceremonial and hospitality, both official and offered by Sir Robert and Lady Mond, who entertained all the delegates to a banquet. The banquet in the Exhibition will remain in the minds of those who were present on account of the artistic and colourful spectacle afforded by a boat anchored in the Seine and under the windows of the dining-hall, for from it rose jets of water coloured by internally reflected lights, governed by a manual on which the executant played as on an organ.

Apart from the excursions to works and laboratories, including one to the Palais de la Découverte in the Exhibition, which is surely its most notable feature for a scientific man, a three days' excursion attended by about a hundred members was arranged to Mulhouse, where the founder, Paul Kestner, was born in 1864, and thereafter to Lausanne, where he died early this year. Sir Robert Mond, having by his side $\mathbf{M}$. Emile Dollfus, president of the Société Industrielle de Mulhouse, paid homage to Paul Kestner, describing his career and his achievements in chemical industry, such as his apparatus for dealing with corrosive liquids, his evaporators, his plant for maintaining constant humidity and temperature and his foundation in 1917 of the Société de Chimie Industrielle, mentioning also his award of the medals of the British Society of Chemical Industry and the honorary membership of the American Chemical Society. But he also made mention of the features of his fine personality and helpfulness, by which he is remembered by many in Great Britain. It was pleasing to see Madame Kestner at this celebration. At Lausanne, Sir Robert laid a wreath on Kestner's grave.

During this part of the programme, visits were made to the potash mines of Alsace and the chemical works of Thann and Mulhouse, where the production of various salts of potassium, of heavy acids, of titanium compounds and much else of interest was shown to the visitors.

In all its aspects, this Congress proved both instructive and enjoyable to the many delegates who attended it.

R. R.

\section{Obituary Notices}

\section{Prof. M. Maclean}

$\mathrm{P}$ ROF. MAGNUS MACLEAN, emeritus professor of electrical engineering in the Royal Technical College, Glasgow, who died on September 2 last, was born in 1858 .

If there was one feature about Prof. Maclean which distinguished him from his academic colleagues, it was his outstanding position in non-academic circles. From a humble beginning in Skye he worked his way to the University of Glasgow and became Kelvin's assistant, lecturer in physics to medical students (1892), and in pure and applied electricity to engineering students (1895), whence he was promoted to the chair of electrical engineering at the Royal Technical College, Glasgow (1899). During this progress, he showed his love of his native Gaelic language by his writing and teaching of its literature. If, therefore, Maclean was pre-eminent as a "great Highlander", he earned his position; and the same admiration which he earned among his fellow clansmen and islesmen he gained in all his other activities, whether masonic or professional. Indeed, wherever Maclean was seen, he was in high places. Should these remarks appear to under-estimate his scientific work, it should be remembered that it is not easy for an outsiderespecially for an Englishman-to appreciate his local influence, no matter whether it be called esteem, hero-worship or what else.

Maclean's appointment to the Royial Technical College preceded the present fine building in George: 